\title{
Pluralidade Linguística na História da Educação Brasileira
}

\author{
Wellington de Oliveira ${ }^{1}$ \\ Wéllia Pimentel Santos ${ }^{2}$
}

\section{RESUMO}

No início do processo de colonização, os portugueses tiveram de conviver com as muitas línguas que eram faladas pelos povos indígenas que ocupavam o território brasileiro. A partir do século XVIII, um Decreto do governo do Marquês de Pombal proibiu o uso da chamada língua geral e demais línguas nativas, impondo ao povo brasileiro a língua portuguesa como língua oficial. Entretanto, muitas línguas indígenas permaneceram, talvez como forma de resistência. O português é a língua oficial do Brasil, mas esse mesmo Brasil é dono de um patrimônio linguístico que conta com cerca de 200 línguas indígenas, além de ter grande influência em outras línguas de origem africana, europeia e asiática. Destarte, o presente trabalho, partindo de uma análise crítica, visa trazer algumas concepções sobre essa diversidade linguística na história da educação brasileira. Para tanto, esta pesquisa faz um breve retrospecto sobre o processo que levou a hegemonização do português falado no Brasil, discute os métodos de repressão aos povos migrantes do sul do Brasil e o processo de extinção das línguas dos povos indígenas, além de trazer uma breve abordagem sobre a variação linguística no que tange ao português falado assim como o escrito. A metodologia aplicada ao trabalho se ateve a um estudo descritivo, do tipo revisão bibliográfica, que se respaldou em literaturas científicas e trabalhos acadêmicos referenciados, que discutem a diversidade cultural e sociolinguística, com enfoques distintos.

Palavras-chave: Diversidade. Língua. Português.

1 Doutor em Educação pela Universidade Federal de Minas Gerais. E-mail: welltha@terra.com. br.

2 Especialista em Criminologia pela Pontifícia Universidade Católica de Minas Gerais. E-mail: welliapimentel@hotmail.com. 


\section{Linguistic Plurality in the history of Brazilian Education}

\section{ABSTRACT}

At the beginning of the colonization process, the Portuguese had to live with many languages that were spoken by the indigenous people who occupied the Brazilian territory. From the eighteenth century, a government decree of the Marquis of Pombal banned the use of socalled general language and other native languages, requiring the Brazilian people to Portuguese as an official language. However, many indigenous languages remained, perhaps as a form of resistance. Portuguese is the official language of Brazil. But that same Brazil owns a linguistic heritage that has about 200 indigenous languages, besides having great influence on other languages of African, European and Asian origin. Thus, the present study, based on a critical analysis, aims to bring some views on this linguistic diversity in the history of Brazilian education. Therefore this research makes a brief review of the process that led to the hegemony of the Portuguese spoken in Brazil, discusses the methods of repression of migrant people in southern Brazil and the process of extinction of the languages of indigenous peoples, and bring a brief approach on linguistic variation in relation to the Portuguese spoken as well as written. The methodology applied to this work adhered to a descriptive study, the type literature review, which is backed by scientific literature and referenced academic papers that discuss cultural diversity and sociolinguistics with different approaches.

Keywords: Diversity. Language. Portuguese.

\section{Pluralidad Linguística en la Historia de la Educación Brasileña}

\section{RESUMEN}

Al comienzo del proceso de colonización, los portugueses tuvieron que convivir con muchas lenguas que eran habladas por los indígenas que ocupaban el territorio brasileño. A partir del siglo XVIII, un Decreto del gobierno del Marqués de Pombal prohibió el uso de lallamada lengua 
general y otras lenguas nativas, imponiendo al puebblo brasileño la lengua portuguesa como lengua oficial. Sin embargo, muchos idiomas indígenas siguieron siendo, tal vez como una forma de resistencia. El portugués es la lengua oficial de Brasil, pero esse mismo Brasil posee un patrimonio lingüístico que tiene alrededor de 200 lenguas indígenas, además de tener una gran influencia en otras lenguas de origen africana, europea y asiática. Así, el presente estudio, basado en un análisis crítico, tiene como objetivo traer algunas concepciones sobre esta diversidade linguística en la historia de la educación brasileña. Por lo tanto, en esta investigación se hace una breve retrospectiva del proceso que condujo a la hegemonización del portugués hablado en Brasil, se discute los métodos de represión a las personas migrantes del sur de Brasil y el processo de extinción de las lenguas de los pueblos indígenas, además de traer un enfoque sobre la variación linguística en relación al portugués hablado, así como escrito. La metodología aplicada al trabajo se basó en un estudio descriptivo, con una la revisión bibliográfica, que se respaldó en literaturas científicas y trabajos académicos referenciados, que tratan sobre la diversidad cultural y sociolinguística, con diferentes enfoques.

Palabras clave: Diversidad. Idioma. Portugués.

\section{Introdução}

O português é a língua materna da quase totalidade de $98 \%$ da população brasileira. Uma realidade bem diferente daquela existente no período colonial quando o português era apenas uma das muitas línguas que se falavam em terras brasileiras.

Com as grandes navegações, a língua portuguesa atravessou o oceano Atlântico na voz dos colonizadores. Quando os portugueses chegaram ao Brasil havia cerca de 1.250 línguas indígenas diferentes, conforme nos apresenta Seki (2000) através de um levantamento de instituições brasileiras nas quais o autor desenvolve um estudo de línguas indígenas e da produção de não missionários sobre essas línguas. Isso implica dizer que tínhamos uma área extremamente multilíngue. Os índios que aqui habitavam eram, em sua grande maioria, falantes de uma mesma língua, a que nós conhecemos hoje por 'tupinambá', conhecida 
também, genericamente, como língua tupi e que os portugueses, já no século XVII, a titularam como 'língua brasílica', contudo, para se comunicarem com os tupinambás, os portugueses eram minorias, assim era condição fundamental de sobrevivência na Amazônia aprender a língua dos nativos.

Mas esse cenário foi alterado a partir do processo de colonização. Já no século XVII os mamelucos, filhos de portugueses com mulheres indígenas, iniciaram a ocupação do norte do Brasil e uma língua diferente foi falada e ouvida às margens do Rio Amazonas.

A língua foi se modificando aos poucos, diferenciando-se um pouco do tupinambá falado pelos índios, passando para a nomenclatura de língua geral amazônica ou ainda a língua nheengatu. A língua geral nheengatu e a língua portuguesa coexistiram até a época das reformas pombalinas.

Na metade do século XVIII, Marquês de Pombal, primeiro ministro de Portugal, tentou mudar a situação em Grão Pará e dar força para sua língua nativa instituindo mais escolas e obrigando exclusivamente o ensino em língua portuguesa, criando, para isso, o Diretório dos índios, datado de 1758, documento pelo qual o ministro legislava a vida dos índios e proibia o uso da língua geral.

Naquele momento histórico, o documento de Pombal volta-se, sobretudo, contra a língua geral, o tupi da costa do Brasil transformado em língua veicular de índios, brancos e negros em vastas porções do território, especialmente na Amazônia, onde também foi e é chamada de nheengatu. $O$ documento marca o início do ocaso desta importante língua veicular, ocaso que vai se acelerar com a chacina de cerca de 40.000 pessoas falantes de nheengatu, índios e negros que pegaram em armas contra a dominação "branca" na revolução denominada Cabanagem, entre 1834 e 1841 (FREIRE, 2004, p. 65).

Tanta repressãoàslínguasindígenasresultounodesaparecimento de boa parte da cultura de várias dessas etnias.

A língua é parte da cultura de um povo e ao mesmo tempo é o instrumento de transmissão e expressão dessa cultura. Assim, na medida em que uma língua desaparece, a memória dessa cultura também desaparece. 
Ainda hoje diferentes povos indígenas resistem à hegemonia da língua portuguesa. Atualmente são faladas no Brasil cerca de 180 línguas indígenas que representam grande diversidade linguística. A maioria delas está na Amazônia, mas, até no Rio Grande do Sul, por exemplo, é falada a língua Kaingang, uma variedade do guarani.

Além da língua portuguesa e das línguas indígenas, outras línguas são faladas em terras brasileiras sendo que há mais de 20 a 30 línguas não indígenas conhecidas como línguas de colonização. Exemplos delas são as variedades de alemão que se fala no Brasil, língua pomerana falada no estado do Espírito Santo, na região de Santa Tereza e também os vários tipos de italiano, lituano e árabe, todas elas, línguas faladas no nosso país por gerações.

\title{
Da Realidade multilíngue para a nossa realidade
}

Usualmente desconhecemos todo o desdobramento histórico da língua portuguesa que a levou a se tornar essa língua hegemônica que é hoje. Contudo, esse foi um processo de muita repressão, não só do ponto de vista linguístico, mas também cultural ou até mesmo físico. Freire, cuja dissertação de doutorado aborda de forma original a história dos usos sociais das línguas na Amazônia discute, pormenorizadamente, as formas de reprodução:

\begin{abstract}
A interação entre europeus e índios, a troca de informações e o processo para disciplinar a força de trabalho indígena através da catequese só podiam viabilizar-se, se fosse superada a enorme diversidade linguística, com o desenvolvimento de uma língua de contato e a criação de uma nova comunidade de fala. (FREIRE, 2003, p. 46).
\end{abstract}

Em relação aos índios, houve uma redução populacional imponente. E ainda hoje, muitas dessas línguas correm risco de extinção já que contam apenas com falantes idosos, que por uma questão cultural não repassam essa língua para os jovens dessas comunidades indígenas.

Parece oportuno verificar que essa situação é decorrente do processo de globalização. Esta entendida como um processo mundial de homogeneização cultural, mas também linguística. E que, conforme 
conjecturam Busnardi e Cassemiro, apesar de aparentemente apenas aproximar culturas distintas, a globalização apresenta dois efeitos, em certa medida, contraditórios.

\begin{abstract}
Uma vez que, ao mesmo tempo em que ela propicia a homogeneização, colocando os países falantes de LI, principalmente os Estados Unidos, como o "centro do mundo", ela também contribui para o fortalecimento do nacionalismo em países não falantes dessa língua, corroborando a heterogeneização existente no mundo. Tais países, não podendo escapar à globalização e ao fato de ser a LI a língua internacional, apegam-se a sua própria cultura como uma forma de não mergulharem tão profundamente na "cultura do outro". (BUSNARDI; CASSEMIRO, 2010, p. 3-4).
\end{abstract}

Estudos recentes de organismos internacionais apontam que a maioria das línguas faladas atualmente, não apenas no Brasil, mas no mundo, estão em risco de extinção.

Ao pensarmos no Brasil, desde o início da colonização, ocorrido no século $X V I$, perpassando pelo século $X I X$ até o século $X X$, podemos perceber que houve um intenso processo de imposição da língua portuguesa causando repressão aos índios e escravos africanos que vieram para o Brasil.

O português falado no Brasil, e mais especialmente na Amazônia, no século XVII, foi considerado, pelo padre Vieira, como uma 'meia língua', produto de uma política colonial, que contribuiu para o extermínio de línguas minoritárias, propiciando a expansão da LGA e a construção de uma espécie de ponte, para que a língua portuguesa pudesse se tornar hegemônica na região. Ambas, LGA e português, na convivência por mais de três séculos, alternaram a função de língua franca, operando como "línguas usurpadoras", pois se expandiram às custas das línguas minoritárias, contando para isso com apoio institucional. (FREIRE, 2003, p. 71).

População contabilizada em torno de 4 milhões de indivíduos que foram retirados do seu universo cultural de origem, e misturados deliberadamente para que não pudessem se comunicar usando suas próprias línguas, sendo reprimidos quando a falavam, já que isso 
representava um risco de motim, de rebelião desses escravos. Essa repressão continuou até o século $\mathrm{XX}$, do ponto de vista da cultura desses povos.

Mas o importante a destacar aqui é a percepção de como esse preconceito cultural se estendeu à língua, e o resultado disso é lamentável porque esses quatro milhões de africanos que vieram para o Brasil falavam cerca de 200 línguas e nenhuma dessas línguas sobreviveu como língua viva, como língua a ser transmitida de pai para filho numa comunidade. Só resistiram línguas no espaço restrito da religião, dos terreiros de candomblé e em algumas comunidades isoladas. Assim, tivemos historicamente um processo de forte repressão linguística em nosso país.

\title{
A repressão aos povos migrantes do sul do Brasil
}

A ocupação do espaço do estado do Rio Grande aconteceu a partir do estado de São Paulo com os tropeiros que foram para aquela região, sobretudo os bandeirantes, levando a língua geral. Esse processo de ocupação do espaço foi diferenciado da ocupação do espaço no Brasil central, pois trazíamos uma questão fronteiriça com o reino espanhol, uma disputa histórica entre eles. Freire explana que:

\begin{abstract}
Pouco se sabe sobre o processo e os métodos de reprodução institucional da Língua Geral entre índios, mestiços e portugueses. Entretanto, tem-se conhecimento de que foi declarada como língua oficial das missões da Amazônia e, em tanto que tal, passou a ser usada com certa sistematização pelos índios de diferentes famílias lingüísticas. (FREIRE, 2003, p. 53).
\end{abstract}

O que é importante elucidar é que com a definição das fronteiras ao sul, a política governamental fixou seus povos nesta região trazendo imigrantes que foram para o Rio Grande do Sul, Santa Catarina, Paraná, ucranianos no Paraná, alemães e italianos no Rio Grande do Sul e japoneses. Com isso havia duas intenções principais: uma delas era a de fixar o trabalhador na região e fixar as fronteiras, mas, sobretudo, a intenção era de 'branqueamento' da população que, em 1835, havia na 
região de Pelotas, 50\% de população negra. Um percentual grande, mas por vezes em número pequeno.

A teoria brasileira do "branqueamento" [...] [é] aceita pela maior parte da elite brasileira nos anos que vão de 1889 a 1914, era peculiar ao Brasil [...] baseava-se na presunção branca, às vezes, pelo uso dos eufemismos "raça mais adiantada" e menos adiantada" e pelo fato de ficar em aberto a questão de ser a inferioridade inata. À suposição inicial, juntavam-se mais duas. Primeiro - a população negra diminuía progressivamente em relação à branca por motivos que incluíam a suposta taxa de natalidade mais baixa, a maior incidência de doenças e a desorganização social. Segundo - a miscigenação produzia "naturalmente" uma população mais clara, em parte porque o gene branco era mais forte e em parte porque as pessoas procurassem parceiros mais claros que elas. (SKIDMO$R E, 1989, p .81)$.

Esses povos que migraram para essas regiões acabaram passando por esse processo de 'branqueamento' cuja ideologia racial nasceu no século XIX,

No exato momento em que os europeus necessitavam de justificativas para a exploração de povos "diferentes". Os europeus acreditavam que o colonialismo imperialista transmitia o progresso econômico e cultural. Africanos e asiáticos eram encarados de forma etnocêntrica como bárbaros e primitivos, enquanto os europeus se consideravam em missão civilizadora. (OLIVEIRA, 2008, p. 6-7).

Atualmente muitos ainda falam suas línguas de origem, mas, com o decorrer de quatro gerações vivendo em território brasileiro fez com que estes povos acabassem passando pelos mesmos processos que os indígenas e os negros ao serem trazidos para o país, sendo que, o diferencial decorre pelo fato dos indígenas e negros serem vistos através de um olhar distinto no que tange ao trabalho em relação ao imigrante e isso favorecia esse grupo. De qualquer maneira, o tipo de visão que se busca obliterar é que o genocídio cultural e linguístico ocorreu também nessas regiões. Lucchesi é o mais representativo de tal postura: 
O genocídio das populações indígenas e a sua resistência à integração à sociedade colonial, sobretudo nos centros urbanos, fizeram com que o negro africano se tornasse o esteio da mão-de-obra da colonização do Brasil. Inserindo-se nos diversos setores da atividade produtiva, mas concentrando-se na base da pirâmide social, os africanos e seus descendentes constituem um elemento fundamental na formação da sociedade brasileira e na expansão da língua portuguesa para todo o território brasileiro. (LUCCHESI, 2010, p. 152).

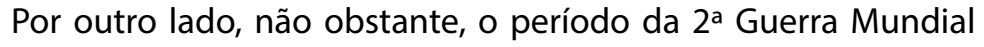
foi crítico. Considerando que os alemães, italianos e japoneses representavam as culturas do eixo que se aliaram ao nazi-fascismo, estes acabaram sofrendo os impactos desse processo de transição dificultado a manutenção de seus laços culturais dentro das impermeáveis comunidades teutônicas. Além disso, lidaram com uma repressão política que excitava e alarmava a população, taxando-os de "inimigos da nação".

Ordenar a sociedade para um só pensamento brasileiro, o alvo do Estado Novo, significava mudar o lugar do indivíduo e das classes nos espaços públicos, negando as diferenças, a pluralidade e quaisquer formas de organização e manifestação que pusessem em xeque a concepção orgânica da sociedade. (CANCELLI, 1994, p. 125).

A esse propósito, Cancelli destaca a criação da Lei da Nacionalização, através do Decreto-lei $n^{\circ}$. 868, embasado no Decreto Federal $n^{\circ}$. 406, de 04 de maio de 1938, cujo objetivo era diminuir a influência e resistência à assimilação por parte das comunidades de imigrantes. Nesta perspectiva,

o governo forçava a adaptação dos estrangeiros à cultura nacional, o qual seria feita pela aprendizagem e uso exclusivo do idioma nacional, portanto, exigia que todos os professores fossem naturais do Brasil, exigia que todo o ensino fosse ministrado em língua portuguesa e proibia a circulação de qualquer material em idioma estrangeiro. Com a ilegalidade do uso do idioma alemão, foi destruído o suporte para a pre- 
servação da memória e da cultura nas comunidades teutas. As escolas que não se submeteram a essa lei foram fechadas. O número de escolas fechadas no país, após 1938, chegou a 1.060, com um total de 40.585 alunos matriculados. (CANCELLI, 1994, p. 126).

Cabe ressaltar que foram os alemães que introduziram a escola no estado do Rio Grande do Sul para a grande população e a partir daí acabaram sofrendo todo um processo de repressão com o advento da Segunda Guerra Mundial.

\section{Etnocentrismo e línguas indígenas}

A situação das línguas indígenas brasileiras e as feições de sua evolução aqui analisadas reforçam as evidências da redução do número de línguas indígenas, e ainda a extinção de várias delas. Tudo isso se deve, não somente à repressão cultural, faz-se necessário, contudo, levarmos em consideração as epidemias que foram responsáveis pela extinção de vários grupos indígenas.

O antropólogo mineiro Darcy Ribeiro (1922-1997), cuja vasta obra tem inegável valor heurístico, manifesta em sua obra, "Os índios e a civilização" (1996), a crença na existência de diversas epidemias que acarretaram no processo de arrefecimento das sociedades indígenas em face do expansionismo ocidental. Entretanto, apesar de sua potencial ameaça de sobrevivência, as línguas são parte da cultura de um grupo. Na medida em que o grupo extingue acaba levando consigo sua língua.

O glotocídio das línguas indígenas é decorrente, muitas vezes, pelo reflexo de um genocídio, do extermínio de uma determinada população. Quando aquela população é extinta, consequentemente aquela cultura e língua também o são. Neste sentido podemos até fazer uma analogia com a questão das espécies animais. Na medida em que uma espécie se perde, a biodiversidade também sofrerá os seus impactos. Temos, assim, uma diversidade cultural e linguística que é afetada na medida em que espécimes são extintas acarretando numa perda de identidade histórica e de uma cosmovisão única.

Vale salientar que esse processo de repressão teve início por volta do século XVI e já estamos no século XXI. Cinco séculos, portanto, 
se passaram e ainda assim podemos notar que essa repressão contra os idiomas indígenas ou contra os outros idiomas que ainda são falados no Brasil permanece. Paul Lewis corrobora ao proferir que "as forças que causam as perdas linguísticas são muitas, e são complexas e interligadas, mas sabemos que o contato prolongado entre os povos, o prestígio de um povo acima dos outros, e as forças econômicas são três fatores principais" (LEWIS, 2010).

Não obstante, atualmente é possível vislumbrarmos algumas ações afirmativas tendo como eixo a aplicação dessas políticas aos povos indígenas de modo a amenizar esse processo repressivo. Conforme Gomes, podemos compreender as ações afirmativas como:

\begin{abstract}
Um conjunto de políticas públicas e privadas de caráter compulsório, facultativo ou voluntário, concebidas com vistas ao combate à discriminação racial, de gênero, por deficiência física e de origem nacional, bem como para corrigir ou mitigar os efeitos presentes da discriminação praticada no passado, tendo por objetivo a concretização do ideal de efetiva igualdade de acesso a bens fundamentais como a educação e o emprego. (GOMES, 2003, p. 27).
\end{abstract}

Temos escolas, principalmente as indígenas, que estão alfabetizando os índios em sua língua de origem sendo que o que tínhamos antes era o ensino da escrita feito por meio da língua portuguesa, haja vista que não havia espaço escolar para o ensino e a continuidade da língua materna desses grupos. Logo, na atual conjuntura, se faz muito importante a revisão do espaço da escola em relação às línguas indígenas.

\title{
A conservação da diversidade linguística sobre os povos indígenas
}

Ao reconhecermos os direitos tanto no que tange aos seus aspectos territoriais quanto culturais dos povos indígenas, permitindo que eles assumam, efetivamente, o controle do seu próprio destino, um dos caminhos para conservação dessa identidade cultural se dá a partir do momento em que o ensino seja feito de forma bilíngue. Isso reforça 
a língua materna lhe dando uma expressão escrita ou um registro mais perene e ampliando o seu espectro funcional no sentido de que ela passa a ser usada para além do uso doméstico restrito. Com isso ela ganha um foro mais amplo dentro do universo cultural.

O Caderno SECAD - Secretaria de Educação Continuada, Alfabetização e Diversidade - no. 3 "Educação Escolar Indígena: diversidade sociocultural indígena ressignificando a escola" ofertado pelo Ministério da Educação traz algumas concepções sobre a educação escolar, de modo a corroborar as formas próprias de organização social, valores simbólicos, tradições, conhecimentos e processos de constituição de saberes e transmissão cultural para as gerações futuras dos povos indígenas. Assim sendo, temos:

O direito a uma Educação Escolar Indígena - caracterizada pela afirmação das identidades étnicas, pela recuperação das memórias históricas, pela valorização das línguas e conhecimentos dos povos indígenas e pela revitalizada associação entre escola/sociedade/ identidade, em conformidade aos projetos societários definidos autonomamente por cada povo indígena - foi uma conquista das lutas empreendidas pelos povos indígenas e seus aliados, e um importante passo em direção da democratização das relações sociais no país. (BRASIL, 2007, p. 9).

Cabe salientar que o despertar de uma consciência para a diversidade cultural que existe hoje na sociedade brasileira reflete um crescimento da consciência social para a diferença de modo elucubrado pelas políticas públicas ao criar novas agendas, compromissos e debates sobre a temática.

Todavia, lamentavelmente, essa consciência para a diversidade ainda não se alojou ao plano linguístico, talvez até devido a certa falta de instrução que existe na sociedade em relação à língua enquanto um objeto plural.

Temos avançado, substancialmente, em termos de educação bilíngue para comunidades indígenas. Agora nos falta maior sensibilidade para o letramento de estudantes das comunidades rurais, da periferia das grandes cidades que falam uma variedade da língua portuguesa diferenciado da variedade padrão, até porque essa 
variedade reflete processos de mudança que aconteceram exatamente no momento em que essa língua foi adquirida por africanos e índios de forma precária, sem um estudo sistemático, se convertendo, portanto, na língua materna desses descendentes.

Há que se destacar, entretanto, que isso provoca mudanças linguísticas que implicam na erosão e composição da estrutura gramatical fazendo com que esses alunos, ao chegarem à escola, se deparem com uma variedade linguística muito distinta. Alguns linguistas chegam a caracterizar essa situação como uma diglossia, sendo este um conceito introduzido, inicialmente, por Ferguson (1959), discutido por Fishman (1965) e alargado por Gumperz (1966) aos dialetos, variantes e registros linguísticos e se constitui numa situação linguística em que duas ou mais línguas são utilizadas no mesmo terreno geográfico de modos diferentes e desempenhando papéis sociais diferentes.

Nesse caso, existe, por exemplo, no espaço da língua portuguesa, a região de Cabo Verde em que esta é a língua oficial da escola e o crioulo é a língua doméstica. Aqui teríamos uma situação análoga, guardadas as devidas proporções.

\section{Violência simbólica e linguagem}

A língua faz parte da cultura de um povo, portanto, não é possível desvinculá-la de sua vertente social. Uma vez que essa língua esteja ameaçada também está ameaçada a cultura. A língua faz parte da cultura, mas também é expressão cultural sendo que as duas estão imbrincadas.

A violência no que diz respeito à língua de uma minoria social, considerada uma violência simbólica, e às vezes, muito mais do que isso, acaba por silenciar as pessoas. Todavia, essa é uma questão que acaba sendo refletida na escola e incide ainda hoje em comunidades bilíngues do sul do país. Segundo Freire:

Quando a escola foi implantada em área indígena, as línguas, a tradição oral, o saber e a arte dos povos indígenas foram discriminados e excluídos da sala de aula. A função da escola era fazer com que estudantes indígenas desaprendessem suas culturas e deixassem 
de ser indivíduos indígenas. Historicamente, a escola pode ter sido o instrumento de execução de uma política que contribuiu para a extinção de mais de mil línguas. (FREIRE, 2004, p. 23).

A escola é um local de recorrente violência simbólica, cultural e linguística, o que acaba por gerar o preconceito. Ela faz parte de uma sociedade que tende a reforçar mitos e valores arcaicos de uma sociedade que necessita de mudanças.

O ensino de uma língua não implica a exclusão da outra já que as línguas são usadas em domínios diferentes. Então é possível que a escola tenha um espaço para o estudo da língua nativa e outro para a língua portuguesa. Por esta via, não é que uma pessoa seja menos ou mais importante porque saiba a língua portuguesa. A questão é que existe um espaço, um domínio em que a língua portuguesa será requerida. $E$ existe outro em que a língua nativa o será. De tal modo, é importante que haja abertura na escola de modo que ela forneça, às pessoas, meios de lidarem bem, tanto na modalidade oral quanto na escrita, com as duas línguas, haja vista que uma não implica na exclusão da outra. Neste sentido faz-se mister que a escola chame a atenção para o fato de onde usar uma determinada variedade da língua e onde usar a outra.

Por falta de maior conhecimento há pessoas que acreditam que devemos falar da forma que escrevemos, quando a lógica da escrita é totalmente distinta da fala. Isso implica dizer que existe uma grande diferença associada à fala e a escrita, sendo socialmente aceita apenas a determinadas intenções estilísticas.

\section{A variação linguística no português falado e escrito}

O preconceito linguístico está disseminado em toda a sociedade. Quando assistimos a programas televisivos, ainda que de humor, que tentam estereotipar determinadas formas de falar, conseguimos vislumbrar a asseveração, não apenas de uma opinião sobre a linguagem, mas, também, a opinião sobre indivíduos. Se uma pessoa nasce falando o português ou uma variedade do português, essa variedade existe para representar uma determinada forma de olhar o mundo. 
Além de expressar ideias, todo ato de fala é um ato de se exibir, de mostrar uma relação com o outro. Portanto, às vezes, se temos uma relação de maior poder, marcaremos isso por meio da linguagem, como marcaremos através de outros mecanismos da cultura.

As relações entre os indivíduos são marcadas, profundamente pela cultura e linguagem. Entretanto, ela é muito complexa de ser defendida. Temos um discurso social que não permite que tenhamos preconceito contra raça, religião ou ainda estado de riqueza, mas contra linguagem continuamos a ser preconceituoso. Essa, portanto, é uma questão fundamental assinalada por Possenti ao refletir:

O preconceito é mais grave e profundo no que se refere a variedades de uma mesma língua do que na comparação de uma língua com outras. As razões são históricas, culturais e sociais. Aceitamos que os outros falem diferente. Mas, não aceitamos pacificamente que os que falam ou deveriam falar a mesma língua falem de maneira diferente. (POSENTI, 1996, p.29).

Paradoxalmente, Bagno (2011) considera que a educação ainda é privilégio de muito pouca gente em nosso país na medida em que uma quantidade gigantesca de brasileiros ainda permanece à margem do domínio das formas prestigiadas do uso da língua.

Assim, tal como existem milhões de brasileiros sem-terra, sem escola, sem teto, sem trabalho, sem saúde, também existem milhões de brasileiros que poderíamos chamar de "sem- língua". Afinal, se formos acreditar no mito da língua única (identificada com a norma-padrão tradicional), existem milhões de pessoas neste país que não têm acesso a essa "língua", que é a empregada pelas instituições oficiais, pelos órgãos - são os sem língua. E claro que eles têm uma língua, também falam português brasileiro, só que falam variedades linguísticas estigmatizadas, que não são reconhecidas como válidas, que são desprestigiadas, ridicularizadas, alvo de chacota e de escárnio por parte dos falantes urbanos mais letrados - por isso podemos chamá-los de sem-língua. (BAGNO, 2011, p. 30).

A variação linguística decorre, fundamentalmente, do fato de que quando falamos não estamos simplesmente comunicando, 
transmitindo uma informação. Estamos, ao contrário, construindo uma identidade, a nossa identidade e a identidade do outro. É nesse processo dialógico em que, enquanto falante, me torno seu ouvinte, e meu ouvinte se torna o falante, estamos interagindo e criando uma imagem um para o outro.

Selecionamos nossas palavras com diversas intenções, ou seja, para impressionar, para transmitir uma relação de poder ou de intimidade. É esse o jogo que está na base do que chamamos de variação linguística.

O indivíduo que domina, por exemplo, o padrão culto da língua - aquele reconhecido como legitimo (correto) pelas instâncias às quais foi socialmente atribuído o direito e o dever de avaliar e classificar as formas de linguagem (sobretudo, a escola e os especialista das áreas de linguagem) - beneficia-se de uma série de vantagens sociais. O domínio da língua culta funciona como uma moeda (um capital) que propicia a quem o possui uma série de recompensas, seja no mercado escolar, seja no mercado de trabalho, seja até mesmo no mercado matrimonial. (NOGUEIRA; NOGUEIRA, 2006).

Vivemos numa realidade muito pautada pelo conceito do falar certo ou errado. É importante termos em mente que a língua que uma pessoa fala, o modo como a pessoa expressa sua língua materna reflete a cultura, o seu grupo social. A partir daí, devemos levar em conta que as pessoas são diferentes e que, inclusive, os diferentes grupos se complementam.

Assim sendo, é necessária a compreensão dessa diferença. Não cabe mais nos atermos ao certo ou errado. Existe uma maneira de falar que faz parte da identidade de cada um. E a questão que se coloca é: essa língua que eu falo corresponde ao ideal linguístico pela comunidade geral a qual eu pertenço?

A partir daí teremos o seguinte: há situações em que é necessário falar de uma maneira sendo esta um pouco diferente daquela que pertence ao meu grupo social de origem. E por isso, deve caber à escola mostrar esse percurso. Isso implica dizer que, há um espaço social em que podemos usar aquela língua que é a pertencente ao meu grupo 
social, aquela língua com a qual eu me comunico em casa, com meus amigos, etc. Mas há outro espaço em que isso não será suficiente. Farse-á necessário, então, o domínio de outra modalidade de linguagem.

Isso denota que nosso repertório linguístico será ampliado cada vez mais e isso irá nos permitir uma circulação por diferentes espaços sociais. Deste modo não podemos entender as diferentes formas de nos comunicar como 'certo ou errado'. Para cada situação precisamos ter um repertório tal que nos permita usar a língua da forma que melhor se adequa.

Com efeito, se tivermos na escola um espaço para lidarmos com a diferença entre língua falada e a escrita, e o professor estiver consciente dessa diferença será fácil lidarmos com essas questões.

Ao fazermos, na escola, por exemplo, a transcrição de uma fala de conversa de adolescentes, teremos ali a presença de várias gírias e marcas que são pertencentes ao estilo casual desse falante. Portanto, nesta situação aquela linguagem será bastante adequada. Agora, ao supormos que essa mesma pessoa vá apresentar um trabalho em sala de aula, aquela modalidade já não será adequada. Logo, podemos perceber que isso não é questão de ser certo ou errado. $O$ tipo de linguagem que o aluno utilizará deverá ser adequado às diferentes situações vivenciadas por ele.

Ao mesmo tempo, se a escola fornece um leque de situações diferentes, naturalmente, o aluno irá perceber que os espaços sociais diferentes requerem performances linguísticas diferentes.

\section{Considerações Finais}

A linguística no Brasil vem avançando e é comum quem ainda esteja tomando contato com o discurso linguístico pensar que tudo seja possível, ou ainda que não seja mais necessário o ensino da língua, haja vista que qualquer modalidade de fala é válida.

Uma questão muito válida para o professor de língua, ao levarmos em conta o ponto de vista do objetivo, continuamos com o mesmo objetivo que têm todos os professores de língua portuguesa: o ensinar o português. 
O objetivo da escola, e do professor de língua portuguesa é esse. Fazer com que alguém entre em sala de aula, ano após ano, e ao final saiba escrever usando a norma padrão e saiba se expressar usando a norma cultuada na sociedade.

Entretanto, a escola não precisa banir do seu universo a variedade popular.É preciso pensarmos ser possível que haja situações no ambiente escolar em que o aluno poderá usar sua variedade materna e que, ao longo do tempo, ele irá aprendendo a outra variedade linguística. $E$ isso não implica em abandonarmos o ensino da norma padrão. Da mesma forma acontece quando uma pessoa aprende a língua inglesa, esta não para de falar a língua portuguesa.

Deste modo não é necessário abandonar o dialeto materno. Isso deve ser feito a partir do ato da fala, pois nenhuma criança aprenderá a norma cultuada se não a praticar. Cabe, portanto, à escola dar 'voz' ao aluno, proporcionar situações, momentos em que este tenha condições de utilizar essa variedade cultuada valendo também para o texto escrito.

Tendemos a gastar muito tempo com aulas focadas em gramática normativa, sendo que, para o aluno semianalfabeto, funcionalmente falando, às vezes, torna-se muito enfadonho se deparar com tais análises profundas, assim é importante focalizarmos no uso da língua, seja por meio da escrita ou da oralidade.

Contudo, necessitamos assumir a língua portuguesa como nossa língua. A língua que nos expressa como indivíduos, que nos permite o convívio social expressando a nossa cultura. E para que isso aconteça contamos com o apoio da escola e sua equipe docente o que implica numa atitude de auxiliar para que os alunos assumam essa identidade linguística da língua portuguesa. Quando os alunos começarem a dizer que aprender o português não é difícil, a partir daí já estaremos começando a resolver o problema.

O que chamamos de norma padrão, considerada a norma ideal, não corresponde ao chamado uso culto da língua. Assim, o primeiro desafio da escola e dos linguistas é o de revermos esse padrão a fim de ajustá-lo à nossa realidade.

O trabalho do professor, não só reforçando a diversidade linguística, se completa no sentido de dar acesso ao aluno a esta 
norma padrão ou norma culta, haja vista que a nossa tradição literária permite ao nosso estudante ler autores clássicos, ou seja, ter acesso à tradição do conhecimento. E na medida em que ele domina esse saber linguístico da norma culta e mesmo da norma padrão, ele terá maior acesso a diferentes linguagens. Porém, isso não poderá constituir numa valoração linguística, pois a norma popular não deve nada em termos de expressividade em relação à grande cultura.

Por fim, são milhões de pessoas que pensam, sonham, se expressam, vivem a língua portuguesa. Formamos uma comunidade de falantes da língua portuguesa com diferentes experiências culturais. A linguagem é uma forma de identidade que permitirá que cada um de nós se mostre através dela. Consequentemente, torna-se mister que o professor esteja aberto para entender, compreender o que o aluno traz de bagagem cultural e linguística para sala de aula.

\section{Referências}

BAGNO, Marcos. Nada na língua é por acaso: por uma pedagogia da variação linguística. São Paulo: Parábola, 2011.

BRASIL. Educação Escolar Indígena: diversidade sociocultural indígena ressignificando a escola. Brasília, DF: SEDAC/MEC, 2007.

BUSNARDI, B.; CASSEMIRO,M.S. O impacto da globalização no ensino de língua estrangeira: conflito entre homogeneização e a heterogeneização cultural. São José do Rio Preto: Unesp, 2010.

CANCELLI, E. O Mundo da Violência: a polícia na Era Vargas. 2. ed. Brasília, DF: Universidade de Brasília, 1994.

FREIRE, José Ribamar Bessa. Trajetória de muitas perdas e poucos ganhos. In: __ Educação Escolar Indígena em Terra Brasilis: tempo de novo descobrimento. Rio de Janeiro: Ibase, 2004.

Da língua geral ao português: Para uma história dos usos sociais das línguas na Amazônia. Tese (Doutorado em Literatura Comparada) - Programa de Pós-Graduação em Letras da UERJ, 
2003. Disponível em: <http://www.taquiprati.com.br/arquivos/pdf/ TeseRioBabelversaofinal.pdf $>$. Acesso em: 31 mar. 2016.

GOMES, Joaquim Barbosa. O debate constitucional sobre as ações afirmativas. In: SANTOS, R. E.; LOBATO, F. (Org.). Ações afirmativa: Políticas Públicas contra desigualdades raciais. Rio de Janeiro: DP\&A, 2003.

LEWIS, M. Paul. Ethnologue: languages of the World. Sixteenth edition. Dallas, TX: SIL International. 2010. Disponível em: < http://www. ethnologue.com/>. Acesso em: 31 mar. 2016.

LUCCHESI, Dante. Africanos, crioulos e a língua portuguesa. 2010. Disponível em: <http://www.coresmarcasefalas.pro.br/adm/ anexos/10122008232732.pdf>. Acesso em: 29 mar. 2016.

NOGUEIRA, Maria Alice, NOGUEIRA, Cláudio M. Martins. Bourdieu e a educação. 2. ed. São Paulo: Autêntica, 2006.

OLIVEIRA, Idalina Maria Amaral de. A ideologia do branqueamento na sociedade brasileira. 2008. Disponível em: <http://www. diaadiaeducacao.pr.gov.br/portals/pde/arquivos/1454-6.pdf>. Acesso em: 31 mar. 2016.

POSSENTI, Sírio. Malcomportadas Línguas. [S. I.]: Parábola, 1996.

SKIDMORE, Thomas E. Preto no Branco: raça e nacionalidade no pensamento brasileiro. Rio de Janeiro: Paz e Terra, 1989. 